\title{
Aoristo)))))
}

International Journal of Phenomenology, Hermeneutics and Metaphysics

\section{A identidade pessoal: a formação da pessoa em Edith Steín}

\author{
Personalidentity: \\ the formation of the person in Edith Stein
}

Prof.essa. Dr.essa Anna Maria Pezzella

Pontificia Università Lateranense di Roma'

\section{RIASSUNTO}

Per Edith Stein l'identità personale è il frutto di un processo che si realizza nel tempo e coinvolge tutti gli aspetti della persona: corpo, anima e spirito. Non si può giungere ad essa senza il contributo di altri esseri umani, mediante la formazione e l' educazione. Tali contributi interagiscono con il nucleo più profondo della persona e, se positivi, unitamente alla volontà del singolo, permettono la formazione di una identità personale consapevole ed equilibrata.

\section{PAROLE CHIAVE}

Identità personale; Corpo; Anima; Spirito; Educazione

\section{ABSTRACT}

For Edith Stein, personal identity is the result of a process that takes place over time and involves all aspects of the person: body, soul and spirit. It cannot be reached without the contribution of other human beings, through training and education. These contributions interact with the deepest core of the person and, if positive, together with the will of the individual, allow the formation of a conscious and balanced personal identity.

\section{KEYWORDS}

Personal identity; Body, Soul; Spirit; Education

\footnotetext{
${ }^{1}$ Email: a.pezzella@pul.it
} 


\section{Aoristo)))))}

International Journal of Phenomenology, Hermeneutics and Metaphysics

\section{INTRODUÇÃO}

A questão da identidade faz parte de uma reflexão antropológica mais ampla, muito aprofundada pela fenomenologia. M. Scheler, por exemplo, se interessa pela antropologia e alguns estudiosos (GEHLEN,1990) o consideram o fundador da antropologia filosófica, porque em Die Stellung des Menschen im Kosmos ele delineia os fundamentos filosóficos da antropologia, identificando no espírito o elemento distintivo do ser humano. Além disso, em Mensch und Geschichte, ele dá uma imagem clara da antropologia filosófica, a qual é uma ciência da essência e da estrutura eidética do ser humano, de sua relação com os reinos da natureza (inorgânico, vegetal, animal) e com o princípio de tudo, Deus. Inclui também o problema psicofísico da relação entre a alma e o corpo e a questão da relação entre o vital e o poético. Somente essa antropologia, segundo o filósofo, poderia dar a todas as ciências, as quais têm como objeto o homem, um fundamento filosófico (SCHELER, 1999, p.23).

Husserl também se interessa pela antropologia, de maneira particular no segundo livro das Ideias, amplamente elaborado e revisado por Edith Stein.

Husserl oferece uma visão antropológica muito precisa e ampla, mas é crítico em relação à antropologia científica da época, pois propunha um significado do ser humano como espécie animal e descrevia quais eram as funções e constituição do ser humano que diferiam das funções dos animais. Esse tipo de antropologia, mais próximo da biologia e da zoologia, baseava-se apenas em uma descrição morfológica e explicações causais, as quais não correspondiam à complexidade do ser humano. Por esse motivo, foi necessário buscar ou mesmo encontrar uma nova antropologia capaz de levar em consideração todo o ser humano, vivente em corpo e alma.

Em uma conferência em $1^{\circ}$ de junho de 1931, na Kantgesellschaft em Berlim, intitulada Phänomenologie und Antropologie, Husserl critica, no entanto, seja a filosofia da vida de Dilthey que uma nova antropologia filosófica que estava provando um sucesso considerável, especialmente dentro do movimento fenomenológico. Essa nova antropologia, mesmo que Husserl não a diga abertamente, nasceu sob a pressão dos estudos de Scheler, que, embora em 1931 não estivesse mais vivo, havia marcado o caminho. Segundo Husserl, para esse tipo de antropologia, apenas em uma teoria essencial da existência do homem mundano (Dasein) estava o verdadeiro fundamento da filosofia (HUSSERL, 1999, p.189). Husserl é crítico em relação a essa antropologia porque, por mais que ele tenha refletido sobre questões antropológicas, residindo no corpo, na psique, no espírito, no ego, na consciência, na motivação etc., seu interesse não era entender como o ser humano é feito concretamente, mas para Husserl era importante examinar a correlação fundamental entre o sujeito e o mundo. Somente desse modo a antropologia poderia não ser mais uma ciência objetiva natural, mas uma ciência universal do espírito. 


\section{Aoristo)))))}

International Journal of Phenomenology, Hermeneutics and Metaphysics

Ao mundo em ato pertence também o homem operante; agindo no mundo a já dado em um ser, o homem o quererá diferente, reconhece nele, de modo detalhado, possibilidades práticas do ser-de-outro-modo e age consequentemente ${ }^{2}$. Portanto, uma antropologia filosófica é uma ciência do espírito somente se analisa a pessoa humana de maneira universal, somente se examina também o tematizar cognoscitivo e todo o caráter egológico funcional, que age em geral, como também qualquer outra ação do eu (HUSSERL, 1973, p.482). Por isso, a antropologia filosófica à qual Husserl tende tem como objeto o eu, o eu transcendental, em base ao qual se constitui toda a realidade.

No que diz respeito a Edith Stein, ao invés, ela, juntamente com outros fenomenólogos, se interessa de antropologia utilizando os instrumentos que a própria fenomenologia oferece. A filosofia se mantém naquilo que Husserl chama primeira epoché que permite de colocar entre parênteses a atitude natural, neutralizando qualquer pré-compreensão que possa perturbar a pura efetividade da investigação, para ir à essência do fenômeno. De fato, Edith Stein não renuncia à redução eidética, através da qual é possível a descoberta da essência do fenômeno, mas por outro lado não radicaliza unicamente a sua reflexão sobre a subjetividade 3 .

Edith Stein se interessa pela antropologia filosófica por vários motivos. $\mathrm{O}$ primeiro entre eles é o interesse pela pessoa, como já mencionado acima; mas, além disso, a investigação antropológica era fundamental para ela no intuito de delinear uma praxe educativa, pois antes de qualquer reflexão sobre a formação e de qualquer intervenção formativa era necessário conhecer a estrutura do ser humano:

[...] pois formação e educação devem aferrar o ser humano na sua totalidade de corpo vivente e alma; é importante para o educador conhecer a estrutura, as funções e as leis de desenvolvimento do corpo humano para saber o que pode ser útil ou nocivo para um desenvolvimento conforme à sua natureza. É igualmente importante conhecer as leis gerais da alma humana para dar-se conta disso na obra educativa (STEIN, 2000, p.55).

\footnotetext{
${ }^{2}$ Livre tradução a partir do texto italiano, Husserl (1973, p.480).

${ }^{3}$ Infatti, in Introduzione alla filosofia, afferma: "Se si è colto totalmente il carattere della filosofia come scienza dell'essenza, allora ben si comprenderà cosa può provocare innanzitutto la convinzione secondo la quale il metodo fenomenologico è richiesto come metodo filosofico per eccellenza, come via per la risoluzione di tutti $i$ problemi filosofici fondamentali. Se teniamo presente che normalmente ed in modo inevitabile ad ogni noesi corrisponde un noema, più concretamente: che ad ogni percezione appartiene necessariamente un percepito, ad ogni volere un voluto e così via, ed in generale che alla coscienza si contrappone necessariamente un mondo, allora ci rendiamo conto che si può fare una descrizione essenziale della coscienza solo se viene compiuta di pari passo la descrizione della struttura del mondo, della costituzione essenziale di tutti i generi di oggetti. Pensata in un compimento ideale, la fenomenologia deve raccogliere in sé i risultati di ogni ontologia e nel chiarire, in tutte le sue forme, il rapporto esistente tra coscienza ed oggetti, deve contemporaneamente risolvere i problemi riguardanti la teoria della conoscenza e dunque quelli della critica della ragione". (STEIN, 1998, p. 50).
} 


\section{Aoristo)))))}

International Journal of Phenomenology, Hermeneutics and Metaphysics

Por fim, tinha em Edith Stein a exigência de mostrar que a pessoa não podia ser entendida unicamente como um ser natural, como tinha acontecido no positivismo, mas que devia ser investigada como ser corpóreo-psíquico-espiritual. Portanto, Edith Stein pretendia fundar, seguindo as pegadas de Scheler, uma antropologia como ciência do espírito. Pretendia estudar a estrutura do ser humano e a sua inserção nas formas do ser às quais pertence: natureza e espírito.

\section{IDENTIDADE PESSOAL}

Uma vez contextualizada a questão antropológica dentro do universo fenomenológico, se pode enfrentar a questão da identidade por Edith Stein. Para fazer a pergunta: O que é a identidade pessoal para Edith Stein? precisamos nos questionar sobre outras respostas: O que é uma pessoa? Qual é a estrutura de um ser humano? Como podemos encontrar uma identidade pessoal? Analisaremos a questão a partir de dois diferentes níveis: o nível filosófico e o nível pedagógico.

De acordo com Edith Stein, a identidade não é uma construção da memória, pois isso não se encontra em um mecanismo psicológico em que a memória estabelece entre impressões mutantes e presente e passado, como J. Locke e D. Hume pensavam, mas é um processo complexo que precisa tempo e contribuições de outros seres humanos, ou seja, relações interpessoais, culturais e sociais. Tais contribuições interagem com o núcleo mais profundo do ser humano e, se são positivas e se encontram a vontade da pessoa individualmente, permitem a realização do sujeito, a formação de uma identidade pessoal consciente, equilibrada, autônoma e livre.

Mas precisamos prosseguir passo a passo. Portanto, precisamos analisar quem é a pessoa humana e qual é a sua estrutura.

Em Potência e ato Edith Stein escreve:

[...] O eu pessoal não é um eu sem ipseidade nem um começo sem conteúdo, mas um ser materialmente realizado em si mesmo, um ser já possuidor de um núcleo. Nem ao menos é, do jeito que é, colocado na existência por si só; ao invés, é colocado num mundo do qual pode tomar conteúdos e vida a causa das aberturas que pertencem ao seu próprio ser. Portanto, o eu é colocado fora do ser original em um sentido análogo, assim como qualquer coisa criada. Entretanto, ele difere de todo e qualquer ser não pessoal, pois mesmo o que é, está em seu poder. [...] O que é, é alguma coisa em parte da natureza ou da matéria que pode e deve moldar e isso é algo que pertence ao seu ser pessoal e espiritual que não reside no seu poder de moldar, mas que lhe é dado como forma através da qual pode e deve moldar a sua matéria [...]. (STEIN, 2003, p. 383-384)

\footnotetext{
${ }^{4}$ La Stein ascolta Scheler più volte a Gottinga, e per quanto ritenga che il suo pensiero non sia rigoroso alla stregua di quello di Husserl ne è molto influenzata. Tra l'altro Scheler cita il testo della Stein, Das Problem der Einfühlung nella seconda prefazione de Der Formalismus in der Ethik und die materiale Wertethik, quella del 1921.
} 


\section{Aoristo)))))}

International Journal of Phenomenology, Hermeneutics and Metaphysics

Se examinamos os aspectos individuais dessa citação, percebemos que o eu pessoal tem um núcleo e é em parte alguma coisa pertencente à natureza, que pode $\mathrm{e}$ deve moldar e é em parte Espírito (Geist), que é dado a ele como a forma que pode e deve moldar a sua matéria. Portanto, o pessoal, quando entra na existência, não é um vazio, não é uma tabula rasa, mas tem um núcleo que "[...] prescreve de antemão como a sua vida pode e deve ser vivida e o que pode e deve se tornar. O que a pessoa é em si mesma é ser atualizado e retido como habitual [...] quando isso acontece, torna-se um ganho para a eternidade [...]"(STEIN, 2003, p. 214). O núcleo é a parte mais profunda de uma pessoa, contém a nossa essência mais profunda, a alma da alma. De fato, isso é o que faz de nós essa pessoa e não outra: cada um de nós tem um núcleo que nos distingue em relação aos outros. Portanto, o ser humano, a pessoa, se torna si mesma quando atualiza as suas possibilidades, ou seja, as possibilidades do seu próprio núcleo. Uma pessoa não pode tornar-se o que ela não é no seu núcleo. Por exemplo, eu não posso me tornar um bom musicista se eu não tenho uma predisposição, uma capacidade em mim, se isso não estiver registrado no meu núcleo. Eu posso aprender a tocar um instrumento, eu posso adquirir até mesmo uma boa técnica com os exercícios, mas eu nunca irei tocar na Royal Concertgebouw Orchestra. No máximo serei capaz de tocar para os amigos ou também ensinar música, mas eu nunca terei alguma coisa a mais que faça a diferença entre um docente musicista e um excelente musicista.

Edith Stein pensa que o núcleo é alguma coisa simples e imutável. O núcleo é

[...] simples [...] não existem partes que possam ser separadas como as partes do corpo material. O que se torna real não se separa do que permanece potencial. Um todo sempre está por trás de tudo o que é real em qualquer momento. [...] algo pertencente ao todo entra no modo de atualidade sem se retirar da totalidade, como algo relativamente autossuficiente, mas conectado com a totalidade (STEIN, 2003, p. 206).

O núcleo é simples e imutável, mas precisa passar da potencialidade para a atualidade, assim que nessa passagem existe uma mudança. Existe uma contradição na visão de Edith Stein? Ela faz um exemplo para explicar essa aparente contradição: "Um raio de luz atinge um pequeno ponto na superfície; o ponto brilhante destaca-se da área escura circundante, mas não é cortado do resto da superfície"(STEIN, 2003, p. 206). Então, que uma pessoa se atualize em relação ao seu núcleo não se desprende do que ainda está em potência e espera para ser realizado.

Para ser realizada como pessoa, é necessário um trabalho constante sobre si mesmo e esse trabalho não pode deixar de levar em consideração todas as peculiaridades do núcleo. O ego pessoal precisa trabalhar sobre si mesmo para realizar as possibilidades implícitas no núcleo.

A esse ponto, é necessário insistir no ego e nas suas peculiaridades para compreender como ele assume o controle sobre si mesmo e pode ser realizado. Como

$$
\begin{array}{r}
\text { Anna Maria Pezzella } \\
\text { Toledo, v. 4, n*2 (2021) p. 28-39 }
\end{array}
$$




\section{Aoristo)))))}

International Journal of Phenomenology, Hermeneutics and Metaphysics

é bem sabido, a fenomenologia e Edmund Husserl trabalharam extensivamente sobre o ego. Husserl escreve:

[...] O Ego é o sujeito idêntico que funciona em todos os atos da mesma corrente da consciência: é o centro de onde toda a vida consciente emite raios e os recebe; é o centro de todos os afetos e ações, de toda a atenção, apreensão, relacionamento e conexão, de toda a esperança e medo e toda tomada de posição teórica, valorativa e prática, de todo prazer e angústia, de toda esperança e medo, de todo fazer e sofrimento. Em outras palavras, todas as particularidades multiformadas da relação intencional com os Objetos, que aqui são chamadas de atos, têm seu necessário terminus a quo, o Egopoint, do qual se irradiam. (HUSSERL, 2011, p. 110).

O ego é a unidade que segura unidas as correntes da consciência, as quais dão unidade à vida da pessoa, que está por detrás das vivências. Quando eu digo Eu, eu digo algo sobre mim mesmo, o que eu sou, o que eu fui, como eu vivi e vivo e o que estou pronto a viver.

$\mathrm{O} \mathrm{Eu}$ ao qual Edith Stein refere é sempre um eu concreto. Mesmo que ela fale em suas obras de um ego puro, como o professor tinha feito, com o passar dos anos ela tende a não compartilhá-lo mais plenamente. Husserl escreve: "[...] qualquer home tem em si um eu transcendental"(HUSSERL, 1961, p. 212), mas ele também diz

[...] o que não deve ser entendido no sentido que o eu transcendental seja uma parte real ou um estrato da alma (o que seria sem sentido), e sim no sentido que o homem, através da consideração fenomenológica de si, torna-se uma objetivação do eu transcendental (HUSSERL, 1961, p.212).

Edith Stein nunca abraça totalmente a visão do ego transcendental, porque ela acredita que a existência humana não se baseia na consciência reflexiva daquilo que vivenciamos. Por outro lado, entretanto, ela não pode negar que por trás de cada ato existe um ego por meio do qual é possível afirmar que um mundo existe e que pode ser apreendido em sua funcionalidade. Ela não compartilha totalmente do peso excessivo atribuído ao ego "[...] ao ego absoluto, ao ego enquanto centro funcional último de qualquer constituição" (HUSSERL, 1961, p. 213).

Para Edith Stein o ego é sempre meu, como também afirma Husserl 5 , e mesmo para o professor o ego nunca pode renunciar a sua peculiaridade e a sua indeclinabilidade pessoal; para ela é preciso investigar nessa indeclinabilidade

\footnotetext{
${ }^{5}$ Para o fenomenólogo, “[...] L'io che attingo nell'epoché [...] è denominato io soltanto per un equivoco, anche se si tratta di un equivoco essenziale, perché quando io cerco di definirlo riflessivamente non posso dire che:questi io sono io, io che attuo l'epoché, io che interrogo il mondo quale fenomeno, il mondo che vale ora per me nel suo essere e nel suo essere-così-e-così [...]" (HUSSERL, 1961, p. 210).
} 


\section{Aoristo)))))}

\section{International Journal of Phenomenology, Hermeneutics and Metaphysics}

pessoal, sem erradicá-la do mundo em que vive, sem renunciar por isso à descrição de sua modalidade de funcionamento e estrutura.

Sabemos que Husserl diferencia o ego real e o ego puro, o último correlato de todos os atos, de todas as experiências vividas. O ego puro não possui suas próprias qualidades e estados: essas são características da psique. O ego puro, segundo Edith Stein, como um inextendido, sem qualidade, pontual, não é capaz de explicar o que está nas profundezas da alma que, ao invés, "[...] tem extensão e profundidade". Enquanto o ego for entendido "[...] como" eu puro ", ele não pode se sentir em casa. Só um ego que tem alma pode sentir-se em casa e, a partir daí, podemos dizer que se sente em casa quando está em si" (STEIN, 2000, p. 132).

Mas o ego está sempre corporificado. A pessoa, como vimos, é uma unidade complexa de corpo, alma e espírito.

O ser do homem - escreve o ser E. Stein - é um composto de corpo, alma e espírito. Na medida em que os seres humanos - de acordo com sua essência - são espírito, sua vida espiritual é uma vida em andamento que entra em um mundo que se revela a eles, enquanto eles ainda mantêm um controle firme sobre si mesmos. [...] A alma humana como espírito sobe em sua vida espiritual além de si mesma. Mas o espírito humano é condicionado tanto de cima como de baixo. Está imerso em uma estrutura material que é alma e molda em uma forma corporal. A pessoa humana carrega e envolve seu corpo e sua alma, mas ao mesmo tempo é carregada e envolvida por ambos (STEIN, 1988, p.386-387).

A pessoa, para Edith Stein, é uma unidade corporal, animado-espiritual, portanto, é uma abstração falar sobre os aspectos individuais, pois o corpo não pode ser separado da alma e a psique do corpo e do espírito. Mas essa separação é um mal necessário para compreender analiticamente todos os aspectos da pessoa humana.

A investigação de Edith Stein se move a partir daquela de Husserl. O ser humano tem um corpo vivo, o Leib, diferente do Körper. Possui figura e campos sensoriais bem definidos; é também o centro em torno do qual se organiza todo o mundo espacial, ponto zero de orientação, a partir do qual é possível identificar o próximo, o distante, o acima e o abaixo etc. O corpo é meu lar inato, do qual não posso me afastar, em que sinto e percebo tudo o que acontece. Stein, antes mesmo de Husserl, reavalia o papel do corpo, o qual nos permite encontrar os outros, estabelecer uma relação com eles e é o lugar de manifestação (Schauplatz) da alma, seu espelho.

O corpo vivo tem vida, alma (Seele) e psique (Psyche). Esses dois aspectos são usados indiferentemente dentro da escola fenomenológica. Durante o período fenomenológico, Edith Stein também usa os dois termos indiferentemente. Mas quando conhece a tradição cristã, os dois termos assumem nuances diferentes. A alma, centro do ser de cada pessoa, conhece-se não por um ato intelectivo, mas pelo

$$
\begin{array}{r}
\text { Anna Maria Pezzella } \\
\text { Toledo, v. 4, n·2 (2021) p. 28 39 }
\end{array}
$$




\section{Aoristo)))))}

International Journal of Phenomenology, Hermeneutics and Metaphysics

sentimento; é um castelo interior, um espaço constituído por várias moradas que devem ser atravessadas para se chegar à união com Deus. Stein aprofunda este conceito lendo a experiência dos grandes místicos, antes de tudo Santa Teresa de Ávila e São João da Cruz.

Nos anos 30, Edith Stein aprofunda esse conceito dando-lhe uma definição extremamente clara. A alma tem duas faces, uma voltada para a natureza, e então é psique, e a outra para o mundo espiritual, e então é espírito. Em Der Aufbau der menschlichen Person e em Endliches und Ewiges Sein, a alma é

O espaço no centro da totalidade corpo-alma-espírito. Como alma senciente, ela habita no corpo, em todos os seus membros e partes, recebendo impulsos e influências dele e trabalhando sobre ele formativamente e com vistas à sua preservação. Como alma espiritual, ela se eleva acima de si mesma, ganhando discernimento em um mundo que está além de si mesmo - um mundo de coisas, pessoas e eventos - comunicando-se com este mundo e recebendo suas influências. Como alma, no sentido mais estrito, porém, habita em si mesma, pois na alma o eu pessoal está em sua própria morada (STEIN, 1988, p.394).

Portanto, a alma é o centro do ser, possui as profundezas em que é imerso o que vivemos. É uma fonte de vida espiritual, um lugar onde se reúne tudo o que escapa da consciência e é a morada do ego. Assim, a alma, embora seja parcialmente psique, não se identifica totalmente com ela, porque a psique está encarnada no ego real com suas qualidades: caráter, instinto, etc. A psique e suas qualidades estão sujeitas a mudanças que dependem das circunstâncias reais e estão sujeitas à categoria de causalidade.

A alma, como Seele, é o centro de um ser espiritual-corporal-animado que não está sujeito a qualquer formação ou transformação, porque só pode crescer e amadurecer. Tudo o que diz respeito a ele está enraizado no núcleo, como vimos.

A alma não está fechada em si mesma, mas aberta para o exterior; ela recebe tudo o que lhe é oferecido pelo mundo em que vive o sujeito. Nesta aceitação do mundo, neste ser dirigido ao mundo, a alma é espírito. Para muitos fenomenólogos, o Geist representa o mundo do significado, o reino do que tem valor, das relações mútuas, da intersubjetividade. O sujeito espiritual é o eu, que tem a possibilidade de sair de si sem nunca se abandonar, abrindo-se aos outros, relacionando-se e penetrando e compreendendo o mundo em que vive. $\mathrm{O}$ eu, do qual brota toda a vida e é consciente de si, não se identifica totalmente com o corpo e a alma, mas os abraça, encerrando-os, de maneira pessoal. Para o conceito de pessoa, portanto, Edith Stein entende o Ego consciente e livre. Ela/ele é livre porque ele/ela é o mestre de si mesmo e de suas ações e porque ela/ele, consciente e deliberadamente, determina o curso de sua vida por meio de atos livres que representam para o fenomenólogo a primeira esfera do domínio da pessoa (STEIN, 1988, p.386-387, 397). 


\section{Aoristo)))))}

International Journal of Phenomenology, Hermeneutics and Metaphysics

\section{A FORMAÇÃO DA PESSOA HUMANA}

Recordando a visão antropológica, Edith Stein, em Der Aufbau der menschlichen Person, afirma que o ser humano é responsável por si mesmo e como tal isso pode e deve "formar" a si mesmo. Venhamos à questão do "eu".

Vamos seguir brevemente o argumento de Edith Stein. Quando dizemos 'ela', nos referimos a alguém, a uma pessoa, que me fala sobre si mesma. Ela/ele é um "eu" e só posso dizer seres humanos e mais ninguém.

Eu olho nos olhos de um animal - escreve E. Stein - e algo de lá me olha de volta. Penetra em uma interioridade, dentro de uma alma, que sente meu olhar e minha presença. Mas é uma alma silenciosa, um prisioneiro [...]. Eu olho nos olhos de um ser humano e seu olhar me responde. Ele me permite penetrar em sua interioridade ou me rejeita. Ele é o senhor de sua alma e pode fechar ou abrir suas portas (STEIN, 2000, p.109).

O ser humano é senhor de si mesmo, uma pessoa livre. Livre significa que ele/ela pode resistir a estímulos e reações impulsivas. Ele é livre e o dever moral nasce dessa liberdade. Como o "eu" é livre, ele pode e deve se formar. A questão, neste ponto, é entender se o "eu" e o "si mesmo" são a mesma coisa. Edith Stein diz sim e não, ao mesmo tempo. $\mathrm{O}$ "si mesmo" tem a chance de refletir sobre si, mas o que se forma e o que está sendo formado não são a mesma coisa. Eles não coincidem completamente. "O ser humano, com todas as suas capacidades psíquicas e corporais é o 'eu' que eu devo formar". Assim, para Edith Stein, o si mesmo não é algo sem forma; ao contrário, é um conjunto de potencialidades que devem ser realizadas por meio da obra do "eu" (STEIN, 2000, p. 116).

$\mathrm{O}$ "Si mesmo" é algo que deve ser formado e isso só pode ser feito pela consciência e pelo Eu livre. Só ele pode e deve trabalhar sobre I Si mesmo e sobre as suas potencialidades.

O ego tem uma força enorme, tem a possibilidade de moldar a alma. Além disso, a mesma alma só pode atingir o fundo se o ego, livremente, decidir fazê-lo, pois ele pode manter relegada às profundezas sentimentos agradáveis ou desagradáveis que comprometeriam uma atividade em andamento. Onde o eu está de tempos em tempos é muito importante para a formação da alma. Quem vive na superfície não tem camadas mais profundas. Neste caso, as camadas estão presentes, mas não atualizadas como poderiam ou deveriam ser (STEIN, 2000, p. 120). Mas o Eu vive na alma, aí está ela, não dá para pensar um Eu sem alma; só na alma o Eu se encontra em casa. Buscar a si mesmo, mergulhar em suas profundezas, compreendendo como um todo e possuir no sentido de se ter nas mãos é, porém, uma questão de liberdade. Portanto, é culpa da pessoa se a alma não atinge a plenitude de seu ser e sua forma (STEIN, 2000, p. 121).

O ego também pode atuar sobre o corpo, treiná-lo através da prática esportiva, pode nutri-lo corretamente e quanto mais perfeitamente o organismo se desenvolve,

$$
\begin{array}{r}
\text { Anna Maria Pezzella } \\
\text { Toledo, v. 4, n`2 (2021) p. 28-39 }
\end{array}
$$




\section{Aoristo)))))}

International Journal of Phenomenology, Hermeneutics and Metaphysics

mais perfeitamente ele é o fundamento, a expressão e o instrumento da alma espiritual-pessoal humana (STEIN, 2000, p. 123).

Se o corpo humano, por ação livre do ser humano, é sujeito a um tratamento correto, se se alimenta e se mantém devidamente praticado, esta formação livre serve ao mesmo tempo à formação espontânea. O objetivo do tratamento intencional serve antes de mais nada para contribuir para o desenvolvimento mais completo e orgânico do corpo; fornecer-lhe os materiais de que necessita e dando às suas forças a possibilidade de realização (STEIN, 2000, p. 122-123).

Isso é possível porque: "Não sou o meu corpo; Eu tenho meu corpo e o domino. Também posso dizer: sou meu corpo. Com o pensamento, posso me afastar dele e examiná-lo de fora. Na realidade, estou ligado a ele" (STEIN, 2000, p. 116). O Eu domina o corpo e pode controlá-lo. A ação livre da pessoa deve ser capaz de moldar o Self. O ego deve perceber o que está presente no poder na pessoa e, mais precisamente, deve colocar em ação o que está no núcleo (Kern), a alma da alma.

O ser humano sozinho, entretanto, não consegue se realizar, mas precisa de ajuda. Obviamente, é necessário o apoio dos adultos e da comunidade para que o jovem encontre a sua plena e autêntica realização. "Que o trabalho educativo escreve Edith Stein - seja primeiro exercido sobre os outros está na ordem do mundo, que fez o primeiro homem perfeito em seu ser, mas para as gerações seguintes ele designou que fossem crescidas e educadas por aqueles que já estavam maduros" (STEIN, 2000, p. 213).

Os seres humanos em statu viae são alunos e educadores (STEIN, 2017, p. 110). “[...] É inegável - sustenta E. Stein - que o ser humano - pelo menos enquanto não puder trabalhar sozinho, livremente, para a sua própria formação - é confiado à ação dos outros, educadores humanos, que podem e devem fornecer-lhe o material necessário para a formação. Visto que a formação do ser humano depende da atividade livre dos que o rodeiam, de suas ações e omissões, eles têm um dever e uma responsabilidade para com ele. Sua intervenção no processo educativo pode, no entanto, consistir apenas em fornecer materiais para o objeto de sua atividade formativa; estes materiais deverão ser tão adequados quanto possível e oferecidos de forma a poderem ser recebidos da forma mais útil. Mas se forem recebidos verdadeiramente, isso não depende mais do educador humano: Paulo plantou, Apolo irrigou - quem o deixou crescer é Deus (STEIN, 2017, p. 70-71).

Portanto, os adultos têm a grande responsabilidade para com os mais jovens, pois eles possibilitam a realização das potencialidades que estão dentro dos mais jovens.

O indivíduo traz ao mundo as forças da natureza humana em geral e aquelas individuais que no decorrer da vida deve e quer desenvolver. Eles só podem ser 


\section{Aoristo)))))}

International Journal of Phenomenology, Hermeneutics and Metaphysics

desenvolvidos se houver a guia dos "adultos", que já estão formados. Stein afirma que esta guia ainda não possui um plano de formação, uma ação educativa planejada em todos os seus aspectos, pois a criança participa "do que" os adultos fazem e faz o que eles exigem. E muitas vezes agem na frente da criança e reclamam a ela sem ter toda uma consciência pedagógica, sem refletir se a ação para a qual - consciente ou inconscientemente - a empurra é adequada para seu desenvolvimento individual e social.

No entanto, a comunidade é fundamental para o sucesso de um projeto educacional. De fato, é a comunidade que deve cuidar de quem faz parte dela e de quem está em processo de formação, porque quanto mais os membros de uma comunidade estão preparados, conscientes, plenamente realizados, mais a comunidade, o Estado, vai crescer, progredir, desenvolver. De fato, Edith Stein enfatiza que, se a pessoa tenta realizar todas as suas habilidades, mas a sua tentativa falha: "[...] apesar do esforço interno, por impedimentos externos, isso é um dano ao mundo espiritual objetivo ao qual algo foge ao invés de enriquecer a pessoa" (STEIN, 2003, p.215). A comunidade que não consegue aceitar e realizar as potencialidades dos seus membros está desenhada a declinar, a morrer. Pelo contrário, uma comunidade que apoia os seus membros, ajuda-os na sua plena realização: vai crescer e se tornar forte.

Portanto, a comunidade joga um papel fundamental no crescimento e na formação do ser humano e, consequentemente, daquele Si mesmo, daquela ipseidade que é o tema desse artigo.

A questão do núcleo é um aspecto extremamente interessante para o argumento em análise, mas é também um aspect extremamente complexo. Edith Stein em Potenz und Akt afirma que

[...] o núcleo é uma coisa simples. [...] não estão presentes nele partes reais que se deixam separar uma da outra como partes de um corpo material. $\mathrm{O}$ que se torna atual não se destaca daquilo que permanece potencial. O inteiro está sempre por detrás de tudo aquilo que de vez por vez é atual. [...] alguma coisa que pertence ao inteiro acede ao modo da atualidade sem separar-se da totalidade, como alguma coisa de relativamente autônomo, apesar de estar unida ao inteiro (STEIN, 2003, p. 206-207).

Poderia parecer uma contradição. O núcleo é alguma coisa de simples e imutável, mas necessita de uma passage da potência à atualidade que tange a sua essência. É o invariável na variabilidade. Edith Stein, para explicar isso, utiliza uma imagem: uma pequena parte de uma superfície, completamente no escuro, é atingida por um raio de luz que provém da obscuridade. Podemos vê-la, a sua potencial visibilidade se torna atualidade, mas não se separa, por esse motivo, do restante da superfície. Portanto, o ser humano, a pessoa, se torna o que é no momento em que torna atuais as potencialidades contidas em si mesmo. É um contínuo e constante 


\section{Aoristo)))))}

International Journal of Phenomenology, Hermeneutics and Metaphysics

trabalho que a pessoa realiza sobre si mesma e é um trabalho que não pode não leva rem conta as peculiaridades do núcleo, pois é este que

[...] predelineia como pode e como deve decorrer a sua vida e o que pode e deve tornar-se. O que ela é em si mesma [...] deve ser atualizado e ser [...] conservado; se isso acontece, é adquirido para a eternidade. O que podia ser atualizado e não foi, fica perdido para a eternidade (STEIN, 2003, p. 214).

\section{CONSIDERAÇÕES FINAIS}

Dou-me conta de que o caminho que nos conduziu até aqui foi articulado, mas quem conhece o pensamento steiniano sabe que não é possível proceder de outro modo e não só porque o seu pensamento é articulado, mas porque em Edith Stein existe uma profunda unidade e radicalidade de pensamento. Uma questão leva consigo uma multiplicidade de reflexões intimamente relacionadas. A reflexão de Edith Stein realmente procede em forma de círculos concêntricos, de modo que, a partir de um argumento a reflexão se amplia sempre mais. Os círculos se tornam cada vez maiores: o maior se apoia no menor para ampliar o próprio raio, apesar de estar contido nele.

\section{REFERÊNCIAS}

GEHLEN, A. Antropologia filosofica e teoria dell'azione. Napoli: Guida,1990.

HUSSERL, E. Fenomenologia e antropologia. In: Fenomenologia. E. Husserl-M- Heidegger. (Ed.) R.

Cristin. Milano: Unicopli, 1999. . Idee per una fenomenologia pura e per una filosofia fenomenológica. v. II. Trad. E. Filippini.

Einaudi: Torino, 2011. La crisi delle scienze europee e la fenomenologia trascendentale. Trad. E. Filippini. Milano: il

Saggiatore, 1961.

Zur Phänomenologie der Intersubjektivität. In: Texte aus dem Nachlass, Dritter Teil: 1929-1935.

HUA XV. (Hrsg.) von I- Kern, den Haag, 1973.

SCHELER, M. La posizione dell'uomo nel cosmo. Roma: Armando, 1999.

. Mensch und Geschichte. In: Gesammelte Werke. v. IX. Berna-Monaco: Francke, 1975.

STEIN, E. Essere finito e essere eterno. Per una elevazione al senso dell'essere. Trad. L. Vigone, (Ed.) A. Ales Bello. Roma: Città Nuova Editrice, 1988.

. Formazione e sviluppo dell'individualità. Trad. Di A.M. Pezzella, A. Togni (Ed.) A. Ales Bell.

Roma: Città Nuova-Edizioni OCD, 2017.

. Introduzione alla filosofia. Trad. A.M. Pezzella. Roma: Città Nuova, 1998.

$\overline{2000}$. La struttura della persona umana. Trad. M. D’Ambra. (Ed.) A.Ales Bello. Roma: Città Nuova,

. Potenza e atto. Studi per una filosofia dell'essere. Trad. A. Caputo. Città Nuova: Roma, 2003.

Submetido: 4 de junho de 2021

Aceito: 4 de julho de 2021

A identidade pessoal: a formação da pessoa em Edith Steín 


\section{Aoristo())))}

International Journal of Phenomenology, Hermeneutics and Metaphysics 